\section{FDM FOR HIGH TECH CERAMICS ON BASE THE ZIRCONIA IN APPLICATION OF DENTAL CROWNS}

DANIEL SIDA, VLADIMIR SIDA

Technical University of Liberec, Faculty of Mechanical Engineering, Department of Material Engineering, Institute for Nanomaterials, Advanced Technologies and Innovations, Technical University of Liberec, Studentska 2, 46117 Liberec, Czech Republic

\section{DOI: 10.17973/MMSJ.2019_03_2018109}

e-mail: daniel.sida@tul.cz, vladimir.sida@tul.cz

Technical ceramics is worldwide known as advanced material for excellent properties like hardness, compression strength, corrosion resistance, electro resistance, as well some of them are unique for the biocompatibility, as well for lot of applications able to use into human body. One of the bottleneck usage the such a sophisticated materials, are low knowledge of fabrication mainly part of the process the shaping. The provide correct ceramic shaping step is the complex of material, design and technology skills, not large widened in present technical staff. One of our target of our investigation was to wipe off the present border between the designer and technologist for ceramics fabrication. And Fused Deposition of the Ceramics (FDC) can be one of the way how to resuscitate the interest in present young technical staff for amazing material like technical ceramics.

Keywords: zirconia, FDC, 3D printing, ceramics, dental crown, bio application

\section{INTRODUCTION}

The idea and motivations for the efforts of 3D printing the ceramics like zirconia, was to find reasonable substitution for present 3D milling technology of production dental crowns.

Today fabrication of the dental crowns is going by two ways. The first one, for lithium glasses materials $\left(\mathrm{LiO}_{2}\right)$ is used already fabricated blanks with metal axe and adjusted one color shade. The material is by standard, but expensive CAD/CAM technology, milled into correct shape according individual design of each requestor. The second one method is focused for zirconia material. The blanks are most use as a disc (for example $\varnothing 100 \times 14 \mathrm{~mm}$ ) green pressed and pre fired. From this is again by diamond or tungsten carbide tooling milled correct shape. Disadvantages for both technologies are: high cost for inputs like materials (waste of blanks is $60 \%$ and higher), machines and low mechanical properties of the material $\mathrm{LiO}_{2}$, the aggressive impact on surface from 3D milling (ceramics is very sensitive for micro notches as a origins of the fatal propagation of cracks).

The first works on FDC for high tech ceramics coming from end of the last century, main efforts was driven by team of Rutgers University. Why was not widely spread this amazing technology into industrial level, in that time the 3D hardware as well software was not on such a level as a today, and very important aspect the price for rep-rap printers today is on reasonable level for all scientific stuff. And maybe focus on non oxide ceramic use for testing on Rutgers University, did not get good impulse for industrial applications, to pull next development.

Today is on the market of rapid prototyping the technical ceramics mainly driven by laser technology and special photo liquids included the grains of the ceramics. All these technologies have major disadvantages, high cost for equipment and very poor mechanical properties due to low density of fired materials. As we have over twenty years practice in ceramic industrial business we focused on two parameters high density=good mechanical properties, cost for inputs mainly for equipment. From analyses of the market we start use simple low cost rep-rap printer for standard FDM technology.

The object of our works have a two task. The first one is the material and technology of extrusion to build the flexible ceramic filament and The second was to adapt standard rep-rap printer to this filament to be able extrude the material through the heated nozzle (hot end).

\section{MATERIAL FOR 3D PRINTING}

As we analyzed today conventional ceramic production, we place the theory to change for the end user just shaping step of the whole process. The target was to use the same entry of the material, and similar binders to help use conventional de binding and sintering equipment of the end user, as well the prototypes shall have similar properties like conventional parts use standard process. Major material properties required for dental applications are, chemical resistance, density, hardness, MOR, grain size, ability to be colored/shades. We tested many materials for extrusion, injection molding, own mixtures, etc. From large development was choose for oxide of zirconia, feedstock able to use in dental applications, $\mathrm{ZrO}_{2} \mathrm{Y}$-TZP. This raw material was modified by additives to be able use for standard extruding the requested filament. We cooperate with EU supplier and result is material able to extrude with temperature $110^{\circ} \mathrm{C}$, elastic and strong enough to be wind 
up on standard spool $\varnothing 10 \times 5 \mathrm{~cm}$. The filament has a diameter $1,8 \mathrm{~mm}$ in variation $+/-0,05 \mathrm{~mm}$.

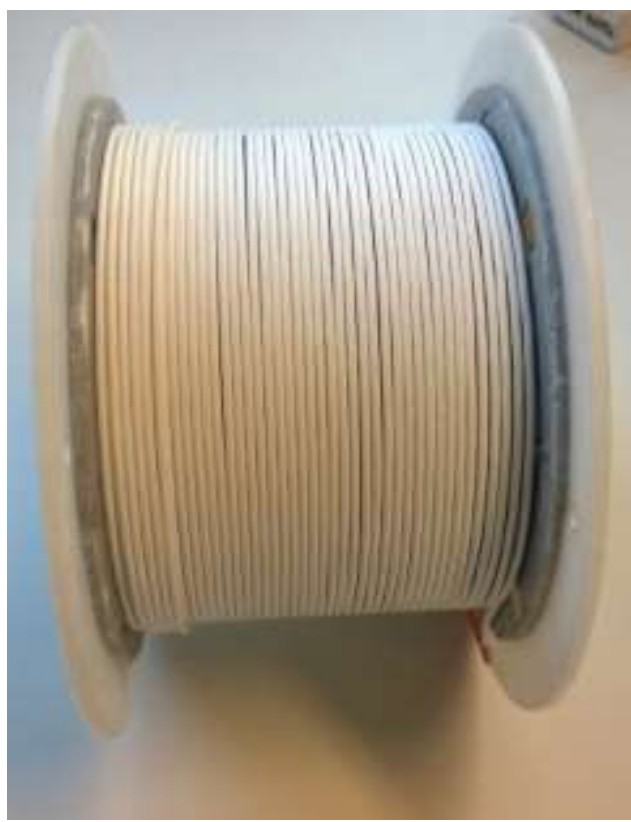

Figure 1. Spool with filament of $\mathrm{ZrO}_{2} \mathrm{Y}$-TZP ready to use

The green density for the filament was over $3,5 \mathrm{~g} / \mathrm{cm}^{3}$, what is good base for buildup correct proto parts in point of view the final mechanical properties. The very important was to arrange system of laying the filament one by one on similar sense without plastic deformation in profile.

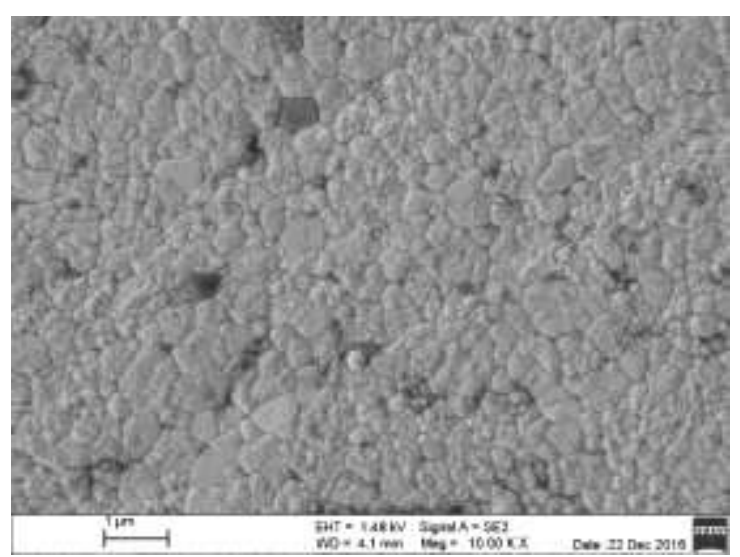

Figure 2. SEM of surface printed material from filament of $\mathrm{ZrO}_{2}$ Y-TZP

\section{FDC 3D printing}

For printing we used the simple rep-rap printing machine with open space to adapt for our needs. During the test we change the rollers for feeding the heating elements, improve all ways to have a smooth distribution the filament to the nozzle. Whole system we add heating elements to keep filament in optimal conditions.
The nozzle was used 0,4 $\mathrm{mm}$, for layer thickness (before firing) $0,25-0,3 \mathrm{~mm}$, and extruding temperature between $100-117^{\circ} \mathrm{C}$. Rest of the process is standard FDM.

For the beginning, we used design from our partner focused on dental or other bio applications. Together we tested all things according standard for dental crowns ISO $6872 / 2008$. Moreover, for investigation the properties we printed few samples in dimensions $5 \times 6.5 \times 31 \mathrm{~mm}$, results see in table below.

\section{DEBINDING}

The technology of sintering is depended on volume the binders in such materials. For the purpose of to reach the best economy, we provide successful tests with process of extraction.

In special solution of the solvents with low controlled temperature you can remove more than $50 \%$ of binders. This can decrease the time for the firing process for $30 \%$. See equipment with small chambers for the dental crowns on figure below.

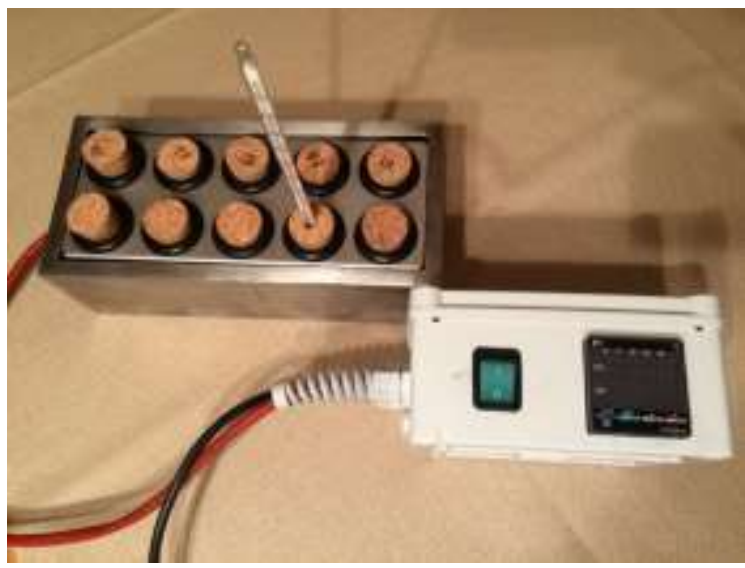

Figure 3. Equipment for the extraction the binders

Sintering, we use conventional kiln for ceramics, used firing temperature was about $1500^{\circ} \mathrm{C}$. Support for firing, was used zirconia microballs.

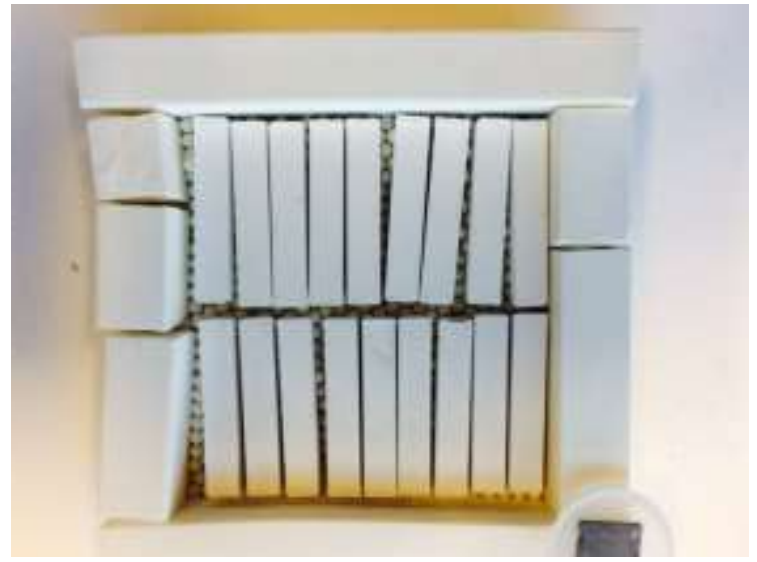

Figure 4. Firing printed ceramic samples-barrs for testing 


\section{CONCLUSION / RESULTS}

After few months of testing we get an positive mechanical properties and printing is start friendly use.

\begin{tabular}{|l|l|l|l|l|}
\hline & Unit & $\begin{array}{l}\text { Requirement } \\
\text { ISO } \\
6872 / 2008\end{array}$ & $\begin{array}{l}\text { Injection } \\
\text { molding }\end{array}$ & FDC \\
\hline Density & $\mathrm{g} / \mathrm{cm}^{3}$ & $\geq 6,0$ & 6,05 & 6,03 \\
\hline MOR & $\mathrm{MPa}$ & $\begin{array}{l}>500 \text { for } \\
\text { dental bridge } \\
3 \text { units }\end{array}$ & $\begin{array}{l}800 \\
(4 \mathrm{pt})\end{array}$ & $\begin{array}{l}775 \\
(3 \mathrm{pt})\end{array}$ \\
\hline $\begin{array}{l}\text { Hardness } \\
\text { HV 1 }\end{array}$ & $\mathrm{GPa}$ & 1250 & - & 1280 \\
\hline Grain size & $\mu \mathrm{m}$ & $\leq 0,6$ & - & 0,4 \\
\hline $\begin{array}{l}\text { Chemical } \\
\text { resistance }\end{array}$ & $\mu \mathrm{g} / \mathrm{cm}^{2}$ & $<2000$ & 0 & 0 \\
\hline
\end{tabular}

Table 1. Compare of the conventional technologies with FDC for $\mathrm{ZrO}_{2} \mathrm{Y}$-TZP

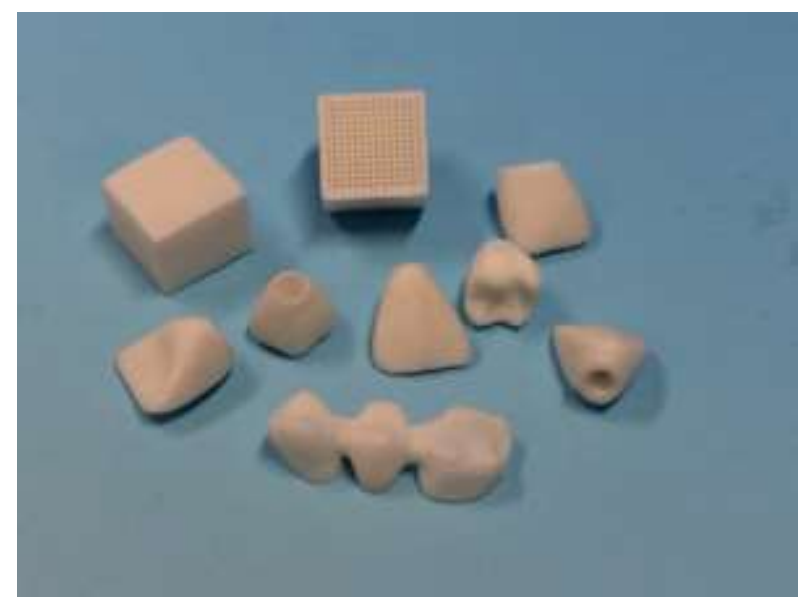

Figure 5. Printed and fired parts for bio applications

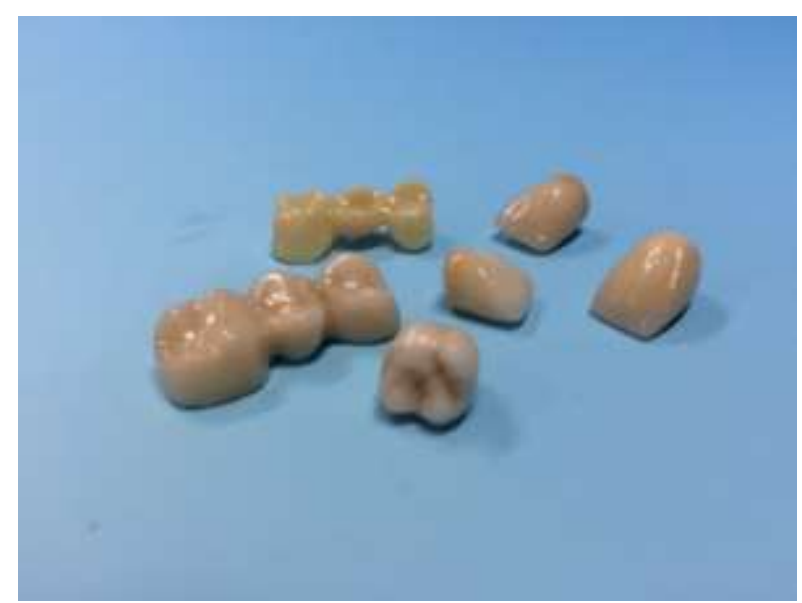

Figure 6. Printed and fired parts for bio applications with aesthetic layers-shades

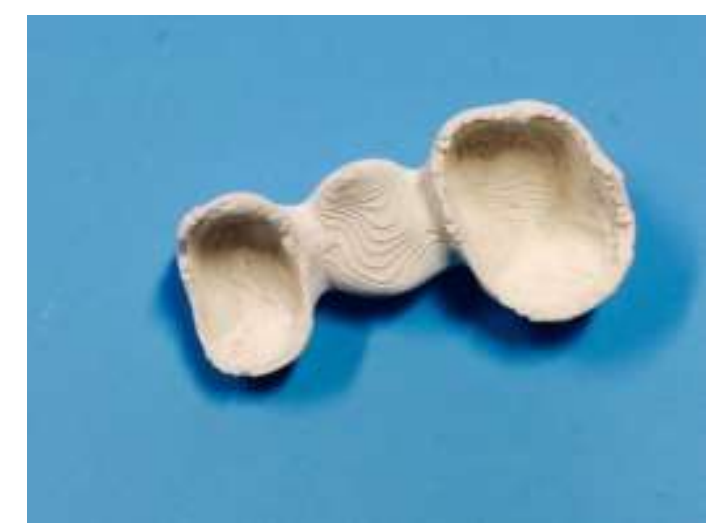

Figure 7. Detail of green printed part of dental bridge

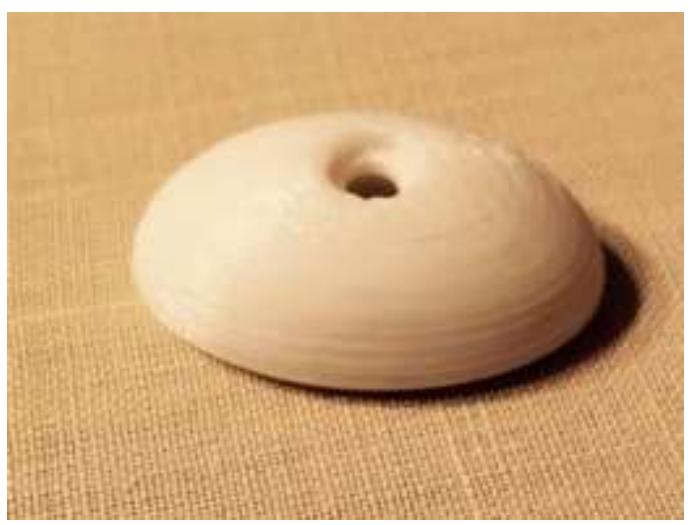

Figure 8. Proto of printed the human small joint design Prospon

Targets of our works were done, the first one material and technology of extrusion to build the flexible ceramic filament were tested and switch in serial. The second was to adapt standard rep-rap printer for the material is use. As well included tests of surface shades and material properties measurement.

\section{Acknowledgement}

This publication was written at the Technical University of Liberec, Faculty of Mechanical Engineering with the support of the Institutional Endowment for the Long Term Conceptual Development of Research Institutes, as provided by the Ministry of Education, Youth and Sports of the Czech Republic in the year 2017, as well part of the project "TA03010930" with the support of the Specific University Research Grant, as provided by the Ministry of Industry, in the year 2016/17. 


\section{REFERENCES}

[Abel 2018] Abel,J.: FFF of Technical Ceramics. Ceram.App.2018,6,36-38

[Balletti 2017] Balletti, C.: State of art and future perspectives. J.Cult.Herit. 2017, 26, 172-182

[Notzel 2018] Notzel,D.: Fused Filament Fabrication of Small Ceramic Components, 2018, Karlsruhe Institute of Technology, Eggenstein/Leopoldshafen, Germany

[Travitzky 2014] Travitzky, N.: Additive Manufacturing of Ceramic Based Materials. Adv.Eng.Mater., 2014, 16,729754 